\title{
DETERMINAN PERILAKU PENGUNAAN ALAT PELINDUNG DIRI PADA PETUGAS KEBERSIHAN
}

\author{
I Gede Purnawinadi, Nadine Meflin Jacob \\ Program Studi Ilmu Keperawatan, Universitas Klabat, Indonesia \\ E-mail: purnawinadi87@unklab.ac.id
}

\begin{abstract}
ABSTRAK
Upaya kesehatan kerja sangat penting untuk melindungi pekerja agar hidup sehat dan terbebas dari gangguan kesehatan. Salah satu jenis pekerjaan yang berisiko terjadinya kecelakaan dan masalah kesehatan kerja adalah petugas kebersihan. Tujuan penelitian ini secara umum adalah untuk mengetahui faktor-faktor yang berhubungan dengan perilaku penggunaan alat pelindung diri (APD) pada petugas kebersihan. Jenis penelitian yang digunakan dalam penelitian ini adalah kuantitatif dengan desain survei analitik melalui pendekatan cross sectional dan uji statistik Spearman Rank. Sampel diambil sebagai representatif dari populasi sebanyak 108 petugas kebersihan menggunakan rumus slovin yang dipilih sesuai dengan metode accidental sampling. Hasil penelitian menunjukkan variabel pendidikan memiliki hubungan yang signifikan dengan perilaku penggunaan APD dimana $p$ value 0,042 dan ketersediaan APD responden $p$ value $=0,00$, sedangkan pengetahuan $(p$ value $=0,909)$ usia $(p$ value $=0,108)$, masa kerja $(p$ value $=0,672)$, dan ketersediaan APD departemen $(p$ value $=0,784)$ tidak memiliki hubungan yang signifikan dengan perilaku penggunaan APD pada petugas kebersihan. Direkomendasikan untuk institusi terkait lebih memperhatikan ketersediaan APD yang dapat digunakan oleh petugas kebersihan sesuai dengan departemen kerja.
\end{abstract}

Kata Kunci: alat pelindung diri, determinan, perilaku penggunaan.

\begin{abstract}
Occupational health efforts are very important to protect workers so that they live healthy and free from health problems. One type of work that is at risk of accidents and occupational health problems is cleaning workers. The purpose of this study in general is to determine the factors related to the behavior of using personal protective equipment (PPE) on cleaners. The type of research used in this research is quantitative with analytic survey design through a cross sectional approach and the Spearman Rank statistical test. Samples were taken as a representative of the population of 108 cleaning workers using the Slovin formula which was selected according to the accidental sampling method. The results showed that the education variable had a significant relationship with the behavior of using PPE where $p$ value was 0.042 and the availability of PPE respondents $p$ value $=0.00$, while knowledge $(p$ value $=0.909)$ age $(p$ value $=0.108)$, years of service ( $p$ value $=0.672)$, and the availability of departmental PPE ( $p$ value $=$ 0.784) did not have a significant relationship with the behavior of using PPE among cleaning workers. It is recommended that related institutions pay more attention to the availability of PPE that can be used by cleaners in accordance with the work department.
\end{abstract}

Keywords: personal protective equipment, determinants, usage behavior. 


\section{PENDAHULUAN}

Bekerja adalah suatu upaya yang dilakukan untuk meningkatkan derajat kehidupan individu, saat bekerja diharapkan lingkungan yang aman dan sehat sehingga pekerjaan dapat selesai dengan efektif dan efisien (Septiningsih, 2017). Secara global, International Labour Organization (2013) menyebutkan bahwa dalam setiap tahun terdapat lebih dari 250 juta kecelakaan di tempat kerja dan lebih dari 160 juta pekerja menjadi sakit akibat bahaya di tempat kerja. Selain itu, terdapat 1,2 juta pekerja meninggal akibat kecelakaan dan sakit di tempat kerja. Sementara di Indonesia jumlah kasus kecelakaan akibat kerja pada tahun 20112014 yang paling tertinggi terjadi pada tahun 2013 yaitu sebanyak 35.915 orang (Pusat Data dan Informasi Kementrian Kesehatan Republik Indonesia, 2015).

Menurut Undang-undang No. 36 tahun 2009 tentang kesehatan, memandang upaya kesehatan kerja sangat penting untuk melindungi pekerja agar hidup sehat dan terbebas dari gangguan kesehatan, serta pengaruh buruk yang diakibatkan oleh pekerjaan. Selanjutnya Undang-Undang Ketenagakerjaan No.13 Tahun 2003 disebutkan pula bahwa pembangunan ketenagakerjaan diselenggarakan atas azas keterpaduan melalui koordinasi fungsional lintas sektoral pusat dan daerah. Perlindungan keselamatan dan kesehatan kerja di Indonesia telah diterapkan dengan dikeluarkannya Undang-undang No.1 Tahun 1970 tentang Keselamatan dan Kesehatan Kerja (Kurniawidjaja, 2012).

Indonesia merupakan salah satu negara yang memiliki tingkat perkembangan industri yang cukup tinggi. Data dari Dinas Tenaga Kerja Provinsi Sulawesi Utara menunjukkan bahwa pada tahun 2015 jumlah kecelakaan kerja di Sulawesi Utara, terdapat 223 kasus kecelakaan, kemudian pada tahun 2016 jumlah kecelakaan kerja menurun menjadi 195 kasus dan pada tahun 2017 (Januari-Juni) baru didapati 7 kasus kecelakaan kerja (Dumbela, Pinontoan, \& Rumayar, 2017).

Salah satu jenis pekerjaan yang rentan menimbulkan kecelakaan dan masalah kesehatan kerja adalah petugas kebersihan. Kecelakaan kerja yang sering terjadi pada petugas kebersihan diakibatkan karena pekerjaan mereka yang selalu terpapar oleh peralatan yang digunakan dan lingkungan kerja. Selain itu petugas kebersihan berisiko tinggi mengalami masalah kesehatan karena terpapar langsung dengan pembuangan sampah (Marlini, 2016). Petugas kebersihan merupakan golongan yang rentan terkena penyakit ataupun kecelakaan akibat kerja. Upaya yang dapat dilakukan untuk menghindari terjadinya penyakit akibat kerja dan kecelakaan kerja adalah dengan APD. Untuk itu APD sangatlah dibutuhkan sebagai kelengkapan yang wajib dikenakan saat bekerja sesuai kebutuhan untuk menjaga keselamatan dan kesehatan pekerja, saat beraktifitas di lokasi tempat pembuangan akhir sampah (Mulasari \& Maani, 2013).

Beberapa faktor yang berhubungan dengan kepatuhan penggunaan alat pelindung diri pada pekerja antara lain usia, masa kerja, ketersediaan APD sehingga kinerja pada pekerja bahkan dapat menimbulkan kecelakaan kerja dan penyakit yang disebabkan pekerjaan. Dengan menggunakan APD, usia yang lebih tua serta sudah lama bekerja maka akan mengurangi kemungkinan kecelakaan kerja dan penyakit. Oleh karena itu penggunaan APD perlu diperhatikan oleh pekerja, perusahaan atau pemilik usaha dan pemerintah setempat (Faniah, 2016). Menurut Novianto (2015) pekerja di PT Sinar Semesta memiliki tingkat pengetahuan yang rendah. Pendidikan juga mempunyai hubungan yang signifikan dengan perilaku pekerja dalam menggunakan APD, pekerja yang tamat SMA akan lebih patuh untuk menggunakan APD dari pada yang tidak tamat SMA (Putri \& Denny, 2014). 
Hasil wawancara Peneliti kepada beberapa petugas kebersihan di Universitas Klabat mengatakan APD tidak terlalu penting yang artinya mereka tidak memiliki pengetahuan yang lebih mengenai pentingnya penggunaan APD dan juga dikarenakan tidak ada sediaan APD yang memadai dan merata disetiap departemen kebersihan. Beberapa informasi dari petugas mengatakan pernah mengalami kecelakaan kerja seperti tergelincir dilantai dan penyakit akibat kerja diantaranya kulit tangan dan kaki yang terkelupas akibat terkena cairan kimia pada saat bekerja. Berdasarkan latar belakang yang telah dibahas, peneliti tertarik untuk melakukan penelitian determinan perilaku penggunaan APD pada Petugas Kebersihan di Universitas Klabat.

\section{BAHAN DAN METODE}

Penelitian ini merupakan penelitian kuantitatif dengan metode survei analitik dengan pendekatan cross-sectional. Metode kuantitatif adalah suatu proses menemukan pengetahuan yang menggunakan data berupa angka sebagai alat menganalisis keterangan mengenai apa yang ingin diukur (Kuntjojo, 2009). Penelitian dengan pendekatan cross-sectional adalah jenis penelitian yang hanya mengambil pengukuran dalam suatu waktu saja (Nursalam, 2008).

Populasi dari penelitian ini adalah pelajar yang sedang bekerja paruh waktu atau full-time, orang tua yang sedang bekerja untuk membiayai anaknya berkuliah, serta orang yang bekerja untuk memenuhi kebutuhan hidup sehari-hari. Sampel penelitian berjumlah 108 petugas kebersihan yang dihitung melalui rumus slovin dari populasi. Tehnik sampling yang digunakan yaitu accidental sampling, yang merupakan teknik penentuan sampel berdasarkan kebetulan, yaitu siapa saja yang secara kebetulan bertemu dengan peneliti dapat digunakan sebagai sampel, bila dipandang orang yang kebetulan ditemui itu cocok sebagai sumber data (Sugiono, 2008). Lokasi penelitian yang dilakukan adalah Kampus Universitas Klabat, Airmadidi Kabupaten Minahasa Utara, Sulawesi Utara mulai bulan Januari sampai Juni 2018.

Sebelum melakukan penelitian, peneliti meminta izin dari departemen kebersihan kampus. Setelah mendapatkan izin, peneliti menjelaskan terlebih dahulu prosedur yang akan dilakukan kepada responden, setelah itu peneliti mangajukan informed consent untuk ditandatangani. Penelitian ini menerapkan prinsip etika autonomy, dimana responden mempunyai hak untuk ikut serta ataupun tidak bersedia menjadi responden dengan bersikap adil (justice) tanpa memihak pada sebagian responden saja. Penelitian ini tentunya bertujuan baik dalam upaya menelaah faktorfaktor yang berperan dalam perilaku penggunaan APD, sehingga prinsip beneficience nyata dalam penelitian ini. Dalam pelaksanaan penelitian ini sedapat mungkin dihindari hal-hal yang berbahaya dan merugikan, sehingga prinsip non-maleficience dapat diterapkan, begitu pula confidentiality sangat dijunjung sebagai suatu kerahasiaan dan melindungi data informasi responden hanya untuk kepentingan penelitian.

Berdasarkan tujuan penelitian yang telah dijelaskan, peneliti hendak mengetahui faktorfaktor yang berhubungan dengan perilaku penggunaan APD pada petugas kebersihan di Universitas Klabat, maka variabel independen terdiri dari pengetahuan, pendidikan, usia, masa kerja, dan ketersediaan alat. Instrumen dalam penelitian ini menggunakan kuesioner untuk mengukur semua variabel. Kuesioner pengetahuan berjumlah 9 pernyataan yaitu: pengetahuan 9 pernyataan, yang diadopsi dari Septiningsih (2017) yang telah diuji validitas dan realibilitas dengan nilai chronbach alpha $=$ 0,724 yang artinya reliabel, dan nilai validitas paling rendah 0.376 dan paling tinggi 0.769 menggunakan taraf signifikansi sebesar $\mathrm{p}<$ 0,05 dan nilai $r$ tabel sebesar 0,361 . Variabel 
penelitian dijabarkan dalam bentuk data berskala ordinal pada tabel berikut:

Tabel.1 Kategori dan Interpretasi Variabel

\begin{tabular}{lllll}
\hline No & Variabel & Kategori & Skoring & Interpretasi \\
\hline 1 & Pengetahuan & 1 & $<56 \%$ & Kurang \\
& & 2 & $56-75 \%$ & Cukup \\
& & 3 & $>75 \%$ & Baik \\
2 & Pendidikan & 1 & - & $\begin{array}{l}\text { Lebih rendah } \\
\text { dari SMA } \\
\text { (tidak }\end{array}$ \\
& & & & sekolah, SD, \\
& & & & SMP) \\
& & & & SMA dan \\
& & 2 & - & sederajat \\
& & & & $<25$ tahun \\
3 & Usia & 1 & - & $\geq 25$ tahun \\
& & 2 & - & $<5$ tahun \\
4 & Masa kerja & 1 & - & $\geq 5$ tahun \\
& & 2 & - & Tidak tersedia \\
5 & Ketersediaan APD & 1 & 0 & Kurang \\
& & 2 & $1-4$ & tersedia \\
& & & & Tersedia \\
& & 3 & 5 & Tidak \\
6 & Perilaku & 1 & 0 & menggunakan \\
& & & & Tidak \\
& & 2 & $1-4$ & lengkap \\
& & & & Lengkap \\
\hline
\end{tabular}

Pengolahan data melalui tahap editing, coding, processing, dan cleaning. Analisis data secara univariat dilakukan untuk gambaran distribusi masing-masing variabel yang diteliti, sedangkan analisis bivariat untuk mengidentifikasi hubungan yang signifikan antara variabel independen dan dependen melalui uji statistik Non-Parametrik Spearman Rank dengan tingkat kemaknaan 95\% $(\alpha 0,05)$ menggunakan program komputer berupa Statistical Program for Service Solution (SPSS). Keeratan hubungan antara variabel digunakan kriteria korelasi sebagai berikut :

Tabel 2. Keeratan Hubungan antara Variabel

\begin{tabular}{cc}
\hline Koefisien Korelasi (r) & Interpretasi \\
\hline $0,00-0,19$ & Sangat Lemah \\
$0,20-0,39$ & Lemah \\
$0,40-0,59$ & Sedang \\
$0,60-0,79$ & Kuat \\
$0,80-1,00$ & Sangat kuat \\
\hline
\end{tabular}

Sumber : Sugiyono (2012)

\section{HASIL PENELITIAN}

Hasil analisis univariat penelitian ini menggambarkan distribusi frekuensi variabel penelitian.

Tabel 3. Distribusi Frekuensi Variabel

\begin{tabular}{lrcc}
\hline \multicolumn{1}{c}{ Variabel } & & Frekuensi & Persen (\%) \\
\hline Pengetahuan: & & & \\
& Kurang & 8 & 7,4 \\
& cukup & 12 & 11,1 \\
& baik & 88 & 81,5
\end{tabular}

Pendidikan:

$\begin{array}{rrr}<\text { SMA } & 14 & 13 \\ \text { SMA } & 94 & 87\end{array}$

Usia:

Ketersediaan APD

$\begin{array}{lll}<25 \text { tahun } & 60 & 55,6 \\ \geq 25 \text { tahun } & 48 & 44,4 \\ & & \\ <5 \text { tahun } & 98 & 90,7 \\ \geq 5 \text { tahun } & 10 & 9,3\end{array}$

responden:

$\begin{array}{rcc}\text { Tidak tersedia } & 26 & 24,1 \\ \text { Kurang tersedia } & 77 & 71,3 \\ \text { Tersedia } & 5 & 4,6\end{array}$

Perilaku Penggunaan APD:

$\begin{array}{rcc}\text { Tdak menggunakan } & 47 & 43,5 \\ \text { Tidak lengkap } & 59 & 54,6 \\ \text { Lengkap } & 2 & 1,9\end{array}$

Tabel 3. menunjukkan distribusi frekuensi pengetahuan petugas kebersihan yang bekerja terbanyak yaitu pengetahuan baik $=81,5 \%$, diikuti dengan pekerja yang berpengetahuan cukup $=11,1 \%$ dan kurang $=7,4 \%$. Mayoritas tingkat Pendidikan berada pada kategori SMA yaitu sebanyak 94 orang $(87,0 \%)$. Dominan usia berada pada usia $<25$ tahun yaitu sebanyak 60 orang $(55,6 \%)$ lalu diikuti oleh responden yang berusia $\geq 25$ tahun sebanyak 48 orang (44,4\%). Responden terbanyak pada masa kerja $<5$ tahun yang berjumlah 98 orang $(90,7 \%)$, diikuti dengan responden pada masa kerja $\geq 5$ tahun sebanyak 10 orang $(9,3 \%)$. Ketersediaan 
APD responden mayoritas pada kategori kurang tersedia yang berjumlah 77 orang $(71,3 \%)$, selanjutnya diikuti oleh kategori tidak tersedia dengan jumlah 26 orang $(24,1 \%)$, dan yang paling sedikit pada kategori tersedia yaitu 5 orang $(4,6 \%)$.

Tabel 4. Hubungan Antara Variabel Independen dengan Dependen

\begin{tabular}{llc}
\hline Valiabel & & Perilaku \\
\hline Pengetahuan & Koefisien Korelasi & 0,011 \\
& Sig. (2-tailed) & 0,909 \\
Pendidikan & Koefisien Korelasi & $-0,196$ \\
& Sig. (2-tailed) & 0,042 \\
Usia & Koefisien Korelasi & 0,108 \\
& Sig. (2-tailed) & 0,276 \\
Masa Kerja & Koefisien Korelasi & $-0,041$ \\
& Sig. (2-tailed) & 0,672 \\
Ketersedian APD & Koefisien Korelasi & 0,933 \\
& Sig. (2-tailed) & 0,000 \\
\hline
\end{tabular}

Seperti terlihat pada tabel 4. menunjukkan hasil analisis hubungan antara pengetahuan dengan perilaku penggunaan APD didapati nilai $\mathrm{p}=$ $0,909>0,05$ berarti tidak ada hubungan yang signifikan antara pengetahuan dengan perilaku penggunaan APD pada petugas kebersihan di Universitas Klabat. Terdapat hubungan yang signifikan $(p=0,042<0,05)$ antara pendidikan dengan perilaku penggunaan APD pada petugas kebersihan di Universitas Klabat dengan koefisien korelasi $r=-0,196$ yang artinya hubungan yang rendah dan arahnya negatif. Tidak ada hubungan antara usia dengan perilaku penggunaan APD pada petugas kebersihan di Universitas Klabat (nilai $\mathrm{p}=$ $0,267>0,05)$. Hasil analisis hubungan anatara masa kerja dengan perilaku penggunaan APD pada petugas kebersihan dan didapati nilai $\mathrm{p}=$ $0,672>0,05$ berarti tidak ada hubungan yang signifikan masa kerja dengan perilaku penggunaan APD. Ada hubungan yang signifikan (nilai $\mathrm{p}=0,00<0,05$ ) ketersediaan APD dengan perilaku penggunaan APD dan nilai koefisien korelasi $r=0,933$ kuat hubungan yang erat dengan arah positif yang artinya semakin tersedia maka semakin lengkap dalam menggunakan APD.

\section{PEMBAHASAN}

Hasil penelitian ini sejalan dengan penelitian yang dilakukan oleh Alhayati, Restuastuti, \& Fatmawati (2014) tentang hubungan pengetahuan pekerja denngan kepatuhan dalam pemakaian APD. Hasil uji statistik penelitian ini diperoleh nilai $p=0,227$ yang artinya tidak ada hubungan yang bermakna antara pengetahuan dengan pemakaian APD. Berdasarkan hasil penelitian ini tidak ada hubungan antara pengetahuan dengan perilaku penggunaan APD. Saat pengumpulan data peneliti melakukan wawancara pada beberapa petugas kebersihan, didapati sudah mengetahui tentang APD, jenis-jenis APD, bahaya serta resiko jika tidak memakai APD. Petugas kebersihan lebih cenderung tidak menggunakan APD karena tidak tersedianya APD disemua departemen, APD dianggap hanya hal yang sepele atau cuek, dan kurang nyaman pakai APD.

Sebagian besar tenaga kerja memang memiliki pengetahuan yang baik namun pada kenyataannya pengetahuan baik tidak menjamin pekerja patuh menggunakan APD. Tidak adanya jaminan bahwa pekerja yang memiliki pengetahuan tinggi akan patuh menggunakan APD karena pengetahuan yang dimiliki oleh pekerja hanya sampai pada pengetahuan tingkatan pertama saja, pengetahuan yang sekedar mengingat informasi yang diterima. Pengetahuan pekerja yang tinggi tentang APD karena pekerja hanya mengingat informasi tentang APD namun belum mencapai tingkat memahami dan mengaplikasikan penggunaan APD. Teori Bloom dalam Notoadmodjo (2012) menjelaskan bahwa perilaku tidak hanya dipengaruhi oleh pengetahuan saja (faktor 
predisposisi), akan tetapi dapat dipengaruhi oleh faktor pendukung lainnya, seperti ketersediaan APD.

Hasil penelitian ini sejalan juga dengan penelitian yang dilakukan oleh Putry \& Denny (2014), didapatkan p-value $0,005<0,05$, dengan koefisien korelasi $\mathrm{r}=0,336$ yang artinya ada hubungan tingkat pendidikan dengan penggunaan alat pelindung diri (APD) dan kuat hubungan yang rendah dan arah positif. Sedangkan dari hasil analisis data penelitian yang peneliti dapatkan, menunjukkan arah negatif yang artinya tenaga kerja yang tidak tamat SMA lebih patuh untuk menggunakan APD daripada yang tamat SMA. Dalam penelitian ini, petugas kebersihan yang tidak tamat SMA terdiri dari orang tua yang sedang membiayai uang kuliah anaknya serta membiayai kehidupan sehari-hari dan yang tamat SMA adalah mahasiswa labor, dan didapati yang tidak tamat SMA lebih disiplin dan patuh dalam hal pemakaian APD dibandingkan dengan yang tamat SMA. Berdasarkan hasil wawancara pada beberapa orang tua yang bekerja sebagai petugas kebersihan menyatakan bahwa mereka sudah tua dan merasa mudah sakit. Sehingga mereka lebih cenderung untuk menggunakan APD saat bekerja.

Hasil penelitian ini sejalan dengan penelitian yang dilakukan oleh Yuliana, dkk (2016) dari hasil uji statistik didapat $\mathrm{p}$-value sebesar 0,929 $>0,05$ dimana artinya tidak terdapat antara umur dengan penggunaan APD. Hal ini dikarenakan pekerja petugas kebersihan yang lebih muda tidak menutup kemungkinan untuk memiliki pengetahuan yang lebih baik terkait APD dan penggunaan APD berbeda sehingga yang berusia lebih muda ataupun yang lebih tua memiliki kesempatan yang sama.

Hasil penelitian ini juga tidak jauh berbeda dengan penelitian yang dilakukan oleh Arifin \& Susanto (2012), dengan hasil penelitian p-value sebesar $0,1>0,05$, artinya tidak terdapat hubungan antara masa kerja dengan kepatuhan pekerja dalam pemakaian APD. Analisis tidak ada hubungan karena mayoritas responden dengan masa kerja $<5$ tahun berperilaku menggunakan APD, walaupun tidak lengkap. Begitupula bahwa pekerja yang sudah bekerja (atau) 5 tahun tidak ada dalam kondisi menggunakan APD. Bahkan ada beberapa responden yang sudah lama bekerjapun tidak patuh dalam menggunakan APD, walaupun pengalaman kerja sudah lama tetapi tidak ada masalah kesehatan ataupun kecelakaan kerja.

Berdasarkan pengamatan dan wawancara peneliti kepada beberapa responden didapati departemen tidak menyediakan APD, namun beberapa responden menyediakan sendiri APD seperti sarung tangan, topi, masker yang digunakan saat bekerja.

\section{KESIMPULAN DAN SARAN}

Pendidikan dan ketersediaan APD responden memiliki hubungan yang signifikan dengan perilaku penggunaan APD, sedangkan pengetahuan, usia, dan masa kerja tidak memiliki hubungan yang bermakna dengan perilaku penggunaan APD pada petugas kebersihan di Universitas Klabat.

Direkomendasikan bagi petugas kebersihan baik mahasiswa labor maupun orang tua yang bekerja agar selalu menjaga keselamatan ketika bekerja dengan menggunakan APD yang sesuai dengan resiko pekerjaan. Bagi setiap departemen kebersihan yang ada di Universitas Klabat disarankan untuk selain menyediakan APD yang layak dan sesuai, perlu memberikan edukasi mengenai kesehatan dan keselamatan kerja bagi seluruh petugas kebersihan kampus. Peneliti selanjutnya diharapkan dapat meneliti kembali faktor-faktor yang belum diteliti seperti kenyamanan penggunaan APD. 


\section{DAFTAR PUSTAKA}

Alhayati, D., Restuatuti, T., \& Fatmatwati. (2014). Hubungan pengetahuan dan sikap petugas Laboratorium patologi Klinik dalam menggunakan alat pelindung diri di RSUD Achmad Provinsi RIAU. JOM FK VOL 1, NO 2.

Arifin, B., \& Susanto, A. (2013). Faktor-faktor yang berhubungan dengan kepatuhan pekerja dalam pemakaian alat pelindung diri coal yard . Jurnal Kesehatan Masyarakat, Vol.2, No. 1.

Dumbela, F. M., Pinontoan, O. R., \& Rumayar, A. A. (2017). Peran sistem manajemen kesehatan dan keselamatan kerja dalam mencegah kecelakaan kerja di PT. PLN (Persero) Wilayah SULUT AP2B Sistem Minahasa. E-journal Unsrat, Vol. 6, No 3

Faniah, A. M. (2016). Faktor-faktor yang berhubungan dengan kepatuhan penggunaan APD earplug dan sarung tangan pada pekerja unit perbaikan di PT. KAI DAOP VI Yogyakarta DIPO SOLO Balapan (Skripsi). Yogyakarta: Universitas Muhammadiyah Surakarta

ILO. (2013, 6 13). Kesehatan dan keselamatan kerja di tempat kerja. Diakses dari https://www.ilo.org/wcmsp5/groups/pu blic/---asia/---ro-bangkok/---ilojakarta/documents/publication/wcms_2 37650.pdf

Kemenkes (2015). Pusat Data dan Informasi Kementrian Kesehatan Republik Indonesia. Diakses dari http://www.depkes.go.id/resources/dow nload/pusdatin/infodatin/infodatinkesja.pdf
Kuntjojo, D. (2009). Metodologi Penelitian. Kediri: Universitas Nusantara PGRI

Kurniawidjaja, L. M. (2012). Teori dan aplikasi kesehatan kerja. Jakarta: Universitas Indonesia (UI-Pres).

Marlini, Y. (2016). Sehat bersama sampah. Diakses dari http://www.kebersihan.bandaacehkota.g o.id

Mulasari, \& Maani. (2013). Hubungan antara kebiasaan penggunaan alat pelindung diri dan hygiene dengan kejadian infeksi kecacingan pada petugas. Jurnal ekologi kesehatan Volume 12, Nomor 2.

Notoadmojo, S. (2012). Promosi kesehatan \& ilmu perilaku. Jakarta: Rineka Cipta.

Nursalam. (2009). Konsep dan penerapan metodelogi dan penelitian ilmu keperawatan Edisi 2. Jakarta: Salemba Medika.

Putri, K. D., \& Denny, Y. (2014). Analisis faktor yang berhubungan dengan kepatuhan menggunakan alat pelindung diri. The Indonesian Journal of Occupational Safety, Health And Environment, Vol.1, No.1 Jan-April, 2436.

Septiningsih, E. (2017). Analisis faktor-faktor yang mempengaruhi tingkat kepatuhan penggunaan alat pelindung diri pada petugas kebersihan di Yogyakarta (Skripsi). Yogyakarta: Universitas Muhammadiyah

Sugiono. (2008). Metode penelitian kualitatif, kuantitatif, R\&D. Bandung: Alfabeta.

Yuliana, S., Hartanti, R., \& Prasetyowati, I. (2016). Faktor yang berhubungan 
dengan Penggunaan alat pelindung diri secara lengkap pada Bidan. e-jurnal pustaka kesehatan, Vol.4, No.2, 337344. 